\title{
South African Police Services Officials' Perceptions of Community-Police Relations in Durban, South Africa
}

\author{
Siyanda Dlamini*
}

\author{
The Durban University of Technology, Centre for General Education, South Africa
}

\begin{abstract}
Police officers' views about police-citizen relationships are shaped not only by opportunities to interact with community residents during normal police work but also in part by efforts due to the larger police mission of encouraging and supporting such attitudes. In recent years, police in different countries has shifted from the traditional reactive form of policing towards community-oriented approaches. Hence, the purpose of this paper is to explore police officers' views of citizen-police relationships and community policing in Durban, South Africa. A qualitative research approach was adopted, to explore such perceptions in the study area. The findings collected through semi-structured interviews with the South African Police Services personnel suggested that police officer were dissatisfied and at best ambiguous about citizens' participation in crime prevention activities or support for the police in a township dwelling. However, in a suburban area, the perceptions marked an improvement in their attitudes on various dimensions. These include officers' views about the overall police mission, increased emphasis on service-oriented policing in contrast to a law enforcement approach, support for community policing, perceived citizens' willingness to cooperate with the police in crime prevention activities, and decreased cynicism about citizens. These findings suggest confidence in the utility of community policing ideas.
\end{abstract}

Keywords: Community Policing, South African Police Service, Community-Police Relations, Durban.

\section{INTRODUCTION}

Crime is a global challenge that threatens not only the safety and security of communities but also the peace and stability of the country itself. The evidential scourge of crime remains a permanent feature of serious magnitude in South Africa as the country persistently tops the global crime index (Dlamini, 2020). South African national crime surveys show that South Africa has never had what one would call the cleanest image. While a strong contributor to the Commonwealth in terms of finances and culture, South Africa has also had a long history of crime. The police released South Africa's 2016/17 crime statistics on the 2nd of September 2017 and they did not make for good reading. There was an increase in crimes such as murder, attempted murder; common assault, robbery with aggravating circumstances, house robbery, and the hijacking of cars. However, not all forms of crime increased with decreases in the assault with the intent to inflict grievous bodily harm, common robbery, house burglary, vehicle theft, and drug-related offences, and rape. The high rates of crime in the South compromises the quality of life of ordinary people in many ways. The impact of crime on the social and economic life of a country urges for crime solutions that work. Moreover, there is scholarly agreement that costeffective and efficient policing requires a joint approach by the police and communities, as well as a strong

${ }^{*}$ Address correspondence to this author at the Durban University of Technology, Centre for General Education, 19 Aberfeldy Street, Scottsville, Pietermaritzburg, 3201, South Africa; Tel: 033845 8811;

E-mail: SiyandaD1@dut.ac.za political will to deal with crime. A key element of all police work is how police officers perceive their relationship with the community and the extent to which they believe citizens cooperate with them. This is significant given that the nature of police work not only brings them in close contact with citizens but also often does so in an adversarial way. Therefore, in modernday societies, one of how the lives of ordinary citizens can be improved is for police agencies to involve communities as active partners in the fight against crime. It is precisely in this context that the primary objective of this paper is to explore police officers' views of citizen-police relationships and community policing in Durban. Furthermore, this paper aims to suggest evidence-based strategies to improve community-police relations in a South African context.

\section{COMMUNITY POLICING: INTERNATIONAL PERSPECTIVES}

Since its introduction in the United States of America during the 1970s, community policing has achieved an enviable position and is now a standard ideological and policy model guiding mission statements, goals, and reform programs of most police forces across the world (Marenin, 2009). Nevertheless, community policing as a strategy remains ambivalent, as there are competing views on the role that communities should perform in the policing framework (Wisler \& Onwudiwe, 2009). This lack of clarity accounts for misunderstanding and inconsistencies when it comes to the implementation of community policing in different countries. Globally, there are 
different models of community policing and different police agencies have implemented it differently.

\subsection{The Chicago Strategy: United States of America}

The Chicago Alternative Policing Strategy (CAPS) was started in 1993 as a pilot programme in five diverse neighbourhoods in Chicago in the United States (US). The goal of CAPS was to encourage community members and the police to work together to reduce crime. During this period, the crime rate was on the rise, the public was growing increasingly fearful of crime and the police were frustrated by their inability to control crime while working in isolation from the community. Relations between the police and the community were strained and there was no trust between the police and the community (Skogan, 1995). The Chicago Police Department, in conjunction with other city agencies and the community, sought to engage the public in community policing (Stevens, 2002). The establishment of CAPS was based on an understanding that, if police, residents, and other agencies worked together, crime rates could be reduced. The motto of the strategy became "Together We Can." Crime declined in the period after the partnership was formed significantly, and the quality of life improved. The community and the police trust each other and work together on solving problems.

CAPS is a community-oriented philosophy of policing and crime prevention involving the police, community, and other government agencies working together to identify and solve the crime. The strategy was designed to meet the specific needs of Chicago (Stevens, 2002). Four key elements define the strategy namely: expanded police presence on the beat, community involvement, support from other agencies, and proactive problem-solving. Five districts in Chicago were selected to pilot the strategy. The strategy was a great success and, based on this, was later expanded to other districts. CAPS set an example of what effective partnerships can accomplish.

Policing is arguably an institution characterised by challenges and obstacles often difficult to overcome. Therefore, many countries have had trouble in decisively dealing with crime, owing to global technological advancements and developments. Furthermore, developments and advancements in crime have also overwhelmed technological resources strangely and indescribably. Therefore, the reason the above international country was chosen as an example is that policing strategies, policy frameworks, systems and models are forced to assume the status of flexibility as in the case of global markets, to meet the demands of evolving flexible criminal activities. Hence, to determine whether South African policing systems, policies, models and frameworks are effective and workable, it was necessary to compare such with worldwide trends and systems in policing.

\section{COMMUNITY POLICING IN SOUTH AFRICA}

The South African elections of April 1994 ushered in a democracy and redefined the political and social context within which policing in South Africa was revolutionised. As already indicated in the previous chapter, the South African Police Service (SAPS) was established on 27 January 1995 in terms of section 214 of the Interim Constitution of the Republic of South Africa, 1993. The Constitution of the Republic of South Africa, 1996, consequently makes provision under section 205 for the establishment of a National Police Service that is transparent, accountable, representative, legitimate and impartial. The Constitution further prescribes in section 222 community policing as the style of policing to be adopted by the SAPS as a vehicle to improve policecommunity relations and, in general, service delivery to all its citizens.

These requirements stipulated in the Constitution demand a fundamental reassessment and transformation of the nature and style of policing in South Africa from denying the human rights of most South Africans during the 'apartheid-era' to gaining the trust and respect of all. This includes changing the basic assumptions of the individual police officer concerning the organisation and its environment. The Constitution of the Republic of South Africa, 1996 prescribes that community policing must be adopted so that the SAPS can obtain greater public legitimacy and acceptance and in general improve service delivery to all South Africa's citizens. Through these provisions, the Ministry of Safety and Security developed and implemented several policies, plans, and strategies to give meaning to the prescripts of the Constitution.

Community policing has generally been viewed as the responsibility of a particular function within the SAPS (Pelser, 2002:24). This responsibility is interpreted at various levels, primarily in terms of the establishment and maintenance of the Community Police Forums (CPF's) and community policing has been interpreted by SAPS members as an add-on 
function to the other responsibilities of the police (Pelser, 2002). This is an indication why, in some police stations in South Africa, community policing is not regarded as an important component of policing. The result of this attitude is that community policing cannot be sustained in the long term. Oliver (2004) opined that for community policing to be effectively implemented, there is a need to plan for its short, medium, and long-term sustainability.

Koning (2000) argues that the government has the moral and constitutional obligation to guarantee a safe and secure living environment for society by upholding law and order. This is usually done through the establishment and implementation of policing structures, programs, and strategies together with adequate delegated authority to implement these. Thus, community policing was established in postapartheid South Africa to help in securing a safe and secure environment for its people.

\subsection{Some Factors Affecting Community Policing in South Africa}

While community policing in South Africa was founded on the above values, its operationalisation has not been without challenges. Below are some of the challenges that are worth noting:

\subsubsection{Police Organisational Culture}

Police culture is best defined as the values, norms, perspectives, and craft rules that inform police conduct (Verma, Das \& Abraham, 2013). Culture is the foundation on which a social group functions (Palmiotto, 2011:35). Purpura (2001) defines culture as the system of values and meanings shared by a group or society. Police culture is also seen as an occupational culture as it provides a shared lifestyle (Stevens, 2003). The police subculture is marked by certain differences from the dominant culture, such as their occupation, training, knowledge of crime, and caution when dealing with citizens when on duty (Purpura, 2001). The police subculture is an essential element of the police's reaction to crime, dealing with any other issues about their mandate, and the level of cooperation and partnership between the police and the community (Verma et al. 2013).

Police subculture can either be positive or negative and has a significant influence on officer behaviour (Skogan, 2006). Studies indicate that officers who hold negative attitudes towards community members find the transformation process in the SAPS difficult to accept. According to Thibault, Lynch, and McBride (2004), the police must overcome their resistance to change and turn the established police culture into a positive force through proper planning and training.

\subsubsection{Resistance to Change}

Resistance to change appears to be a contributing factor in the slow transformation of the SAPS. Officials who resist change do not always understand what community policing means about their current and future functions. There is the fear of the unknown, as they feel that their power and authority as police officials are being eroded. Some officials do not believe that community policing is the way forward, and often these officials act in contradiction to the spirit of community policing. These individuals will sometimes express their lack of support of community policing openly. In situations like these, police management finds it difficult to implement community policing (William, 2010).

According to Van Graan (2008:84), change is stimulated by rapid environmental change and uncertainty. Schwarz and Shulman (2007) argue that organisations of all kinds must deal with regulatory, cultural, economic, technological, and physical environments that are potentially changing more rapidly than the organisations themselves. This means that the pressure on organisations to adapt and change structures and culture is a major challenge. The main objective for transformation and restructuring in the SAPS was to ensure a change of attitudes. The management of the SAPS can play a significant role in facilitating change by encouraging officials, particularly at the lower levels, to adapt to changes.

\section{METHODOLOGY}

This paper adopted a qualitative research approach. This approach used a phenomenological design that is both descriptive and exploratory. For this study, the use of a qualitative research approach enabled an in-depth appreciation of the participants' responses and a detailed understanding of the SAPS officers' views of citizen-police relationships and community policing in Durban.

\subsection{Study Population}

The data for this study were collected in two locations in Durban namely: Glenwood suburb and Cato Manor Township. The sample consisted of twenty (20) police officers from the South African Police 
Table 1: Table for the Selected Study Sample

\begin{tabular}{|c|c|c|c|c|}
\hline $\begin{array}{c}\text { SAPS: Station } \\
\text { Commanders }\end{array}$ & $\begin{array}{c}\text { SAPS: } \\
\text { Sector Managers }\end{array}$ & $\begin{array}{c}\text { SAPS: } \\
\text { Detectives }\end{array}$ & $\begin{array}{c}\text { SAPS: Warrant } \\
\text { Officers }\end{array}$ & $\begin{array}{c}\text { SAPS: } \\
\text { Constables }\end{array}$ \\
\hline \hline 2 & 4 & 6 & 4 & 4 \\
\hline
\end{tabular}

Services. Their complex and detailed understanding of the views of citizen-police relationships and community policing in the study area was explored.

\subsection{Sampling Procedures}

To select the participants of this study, purposive sampling was used. This sampling method is based entirely on the judgement of the researcher. Researchers rely on their experience, ingenuity, and previous research findings to obtain participants deliberately to ensure that the sample obtained may be regarded as representative of the relevant population (Huysamen, 2001). Purposive sampling involved handpicking participants from the target population (SAPS). This sampling was relevant to this study because the participants selected informed the researcher's understanding of the area of investigation. The information collected provided the appropriate and relevant data required to illuminate the researcher's understanding of community-police relations and community policing.

\subsection{Data Collection Techniques}

The study required the participants to be able to express their views and perceptions freely, therefore, it utilised interviews to collect data. Interviews are a method of gathering information through an oral transformation using an interview schedule. Shneiderman and Plaisant (2005: 314) highlight that using interviews has the following advantages:

- They allow for the obtaining of detailed information.

- Direct contact with the participants leads to specific and constructive suggestions.

The study used a semi-structured interview schedule as it allowed the researcher to use the preplanned schedule, and it allowed for elaborate discussions between the participants and the researcher. The interviews where in-depth and done on a one on one this was done to illicit detailed information. The interviews took place at locations that were chosen by the participants and the duration ranged from 20-40 minutes, this was dependent on how much information the participants were willing to share.

\subsection{Data Analysis}

Thematic analysis is a method for identifying, analysing, and reporting patterns (themes) within data as it organises and describes data in detail (Braun and Clarke, 2006). At the heart of thematic analysis, the familiarisation of data by the researcher is important. Data familiarisation was possible because the researcher personally conducted audio-recorded interviews and transcribed them. This process allowed the researcher to familiarise themself with the data for expedited and insightful analysis.

Following this thematic transcription, the scripts were analysed using NVivo version 8 software. This software organised the raw data so that it was possible to link and compare thematic issues within and across documents. The list of "starter nodes" was generated from an initial entry in a project journal in the software where the questions and assumptions brought to the report were outlined. The software gave results that allowed for a deeper examination and management of the qualitative data that might not be possible in traditional coding. Two distinct types of coding were used in the analysis. The first was descriptive coding, which described the cases in the study. This processrelated both to the coding of information in categories and the creation of attributes to clarify them. The second type was analytical coding, which was done by selecting source content to interpret and reflect on the meaning of the data to arrive at new ideas and categories. The process entailed gathering material that could be re-thought and reviewed given the growing understanding of the inter-relationship of the categories in the data.

\section{FINDINGS AND DISCUSSION}

Data interpretation was conducted with the purpose to establish how the SAPS officials perceive community-police relations and community policing in Durban. 


\subsection{Understanding of Community Policing}

The meaning of community policing has seen a variety of interpretations. It was, therefore, important to have a common understanding of concepts related to community policing. The researcher attempted to find out the level of understanding by participants through the key informant interviews. The legislative framework such as the South African Police Service Act and policy frameworks such as the NCPS guided the process of establishing their understanding of community policing. The SAPS Act provides for community policing and other related matters. According to the Act, the police are required to explain to role players what community policing entails. Similarly, the NCPS provides a framework for a multi-dimensional approach to crime prevention. It also defines community policing. The NCPS provides a means by which the SAPS and other government departments, the private sector, and NGOs can integrate their approaches to community policing. Also, the police are required in terms of the South African Constitution to establish community policing, and the philosophy is defined in the Constitution.

Community policing encourages the community and the police to establish partnerships to address the issues of crime, fear of crime, and disorder. Trojanowicz and Bucqueroux (1994) argue that police organisations should not rush into the implementation of community policing without a full theoretical understanding of the concept, community policing. They state that people jump on board without a full appreciation of what community policing is, and what the know-how is to make it work. The morale of police officers working in an environment where relations with communities are not good is often low (Makaudi, 2001). The data for this study showed that those who are actively involved in community policing have different levels of understanding the philosophy as well as their roles and responsibilities.

The participant from the Key Informant Interviews had the following to say:

"Community policing is a partnership between the communities with their local police stations. The community must take ownership of what is happening in their community and together with their local police station must form a partnership. Whereby we all look out for the interests and safety of the people in our community, however, general community members do not understand the notion of community policing, they expect everything to be done by the police alone."

It became evident during the interviews that the level of understanding of what community policing entails depends on how actively involved participants are in this type of partnership. While the senior members of the SAPS had a better understanding of community, policing, junior members at the grassroots level indicated a limited understanding of community policing. From this, it can be deduced that there is a need to educate all role players about community policing to ensure a better understanding by all.

\subsection{Crime Prevention and Combating}

On the responsibility of preventing and combating crime, it was highlighted that there is no single entity that must deal with crime; however, it is the responsibility of every individual within the community. It was also expressed that the government is also responsible for crime prevention; it can do so by elevation of poverty and the provision of employment:

"It is everyone's responsibility to prevent crime and that is also possible if everyone understands their capacity as well. In that, it is everyone's responsibility but I cannot say it is everyone's responsibility and as a civilian, you go out and arrest someone. As you do not have the capacity and you do not have the knowledgeable recourse as to how you can conduct yourself when you do it. As much as they are, something called a citizen's arrest but you have to understand what it entails before. Then the police are responsible for protecting and serving the community. So it cannot be a one-sided approach, everyone must get involved and take action"

\subsection{Support for Community Policing}

When asked, whether all SAPS members support community-policing philosophy, the participants expressed that not all SAPS members support such an initiative:

"No, not all of them. I feel that it should be an interest of all members of the South African Police Services to support the notion of community policing. Because it 
makes your job so much easier, knowing that you have eyes out there. Also for my benefit as well because if I am not out there at that certain point and I have formed a relationship with the community then the community can call me on my phone or send me a WhatsApp or get hold of us via the station, radio control or whatever. There are all these types of communications and ways of getting into contact with one another"

\subsection{Community-Police Relationship}

On the issues of services rendered by the police and partnership between the police and the community, the participants expressed that they are satisfied with the services rendered by the police and the partnership between the police and the community in a suburban area:

"I feel that our police station has taken on quite a very active role in community policing and engaging with the community as they have been seen to be very active in terms of crime statistics and are very reputable when looking at national crime statistics"

However, for the township area, the participants expressed dissatisfaction with the relationship that the police have with the community:

"The police try their best to serve the community, sometimes, I think; the community tends to be unfair to them, especially when they engage in violent protest actions, and sometimes the community Huber a well-known criminal".

It is important to create an understanding and a relationship of trust among the police, the community, and other role players. Trust is regarded as a cornerstone for effective community policing especially, within the South African context. Furthermore, where there is trust, there is less suspicion between role players and this provides an opportunity for collaboration. The police should treat citizens with respect, and the citizens have an equal responsibility to respect the police. Once there is trust, it becomes easier for the citizens to provide information about the crime to the police. The relationship can be bad, indifferent or good, depending upon the attitude, action, and demeanour of every member of the police both individually and collectively.

The reviewed literature indicates that effective community participation/engagement and crime prevention include the following: community members' engagement in operational planning of crime-fighting, community and police participation in patrols, providing police with information during the police investigation, and community participation in arresting by the police. Due to the high number of crimes in the area, there is a need for community members' engagement in operational planning and participation to bring the level of crime down. One of the general principles of community policing is shared responsibility and decision-making as well as sustained commitment, from both the police and community regarding safety and security needs.

\section{CONCLUSION}

In conclusion, this paper aimed to explore SAPS officers' views of citizen-police relationships and community policing in Durban, South Africa. Community Policing scholars worldwide have recognized that one of the major hurdles for successful community-based programmes are misperceptions, as inaccurate as they may be, between the two major actors involved: police and citizens. The overall findings were that SAPS officials in general have more favourable views of the overall mission and understanding of community policing. Secondly, officers in both the suburban and township areas held more positive views of the utility and value of community policing. However, SAPS officials showed favourable attitudes towards citizen-police cooperative efforts and community building in the suburban area as compared to the township area. Finally, police officers in the township area were more cynical about perceived citizen distrust of police. This suggests that it is fair to conclude that generally, the SAPS in Durban do promote community-policing ideas. In a democracy, law enforcement agencies attempt to deliver unbiased services, and the police are held accountable to the public they serve. If this does not happen for any reason, the police should regularly check whether they still meet their mandate.

\section{REFERENCES}

Braun, V. \& Clarke, V. 2006. Using Thematic Analysis in Psychology. Qualitative Research in Psychology, 3, 77-101. https://doi.org/10.1191/1478088706qp063oa

Dlamini, S. 2020. A Comparative Analysis of the Quality of Community Police Forums in Local Cato Manor \& Glenwood 
Communities, South Africa. Cogent Social Sciences Journal. (6) 1.

https://doi.org/10.1080/23311886.2020.1809141

Huysamen, G. 2001. Methodology for the Social and Behavioural Sciences. Cape Town: Oxford University Press Southern Africa.

Koning, D. 2000. Community Policing in South Africa. In: Beer, D. F. \& Swanepoel, H. (eds.) Introduction to Development Studies. 2nd ed. Cape Town: Oxford University Press.

Makaudi, G. S. 2001. Organisational Transformation and the Morale of the Police: A Comparative Study between Potchefstroom and Mafikeng. Masters Thesis, University of Potchefstroom.

Marenin, E. 2009. Report of Community Policing Working Group. Policing in the New South Africa. Durban: Centre for Criminal Justice.

Oliver, W. 2004. Community-Oriented Policing: A Systematic Approach to a Policy Framework for Community Policing. Upper Saddle River, NJ: Pearson.

Palmiotto, M. 2011. Community Policing: A Police-Citizen Partnership, London: Routledge. https://doi.org/10.4324/9780203830505

Pelser, E. 2002. Crime Prevention Partnerships: Lessons from Practice. Pretoria: Institute for Security Studies.

Purpura, P. 2001. Police and Community: Concepts and Cases. Boston: Pearson Publishing.

Schwarz, G. M. \& Shulman, A. D. 2007. The Patterning of Limited Structural Change. Journal of Organisational Change Management, 20, 829. https://doi.org/10.1108/09534810710831046

Shneiderman, S. B., \&Plaisant, C. 2005. Designing the User Interface 4th Edition: Pearson Addison Wesley, USA
Skogan, W. \& Hartnett, S. M. 1995. Community Policing in Chicago, Year Two. NIJ Research Preview. Washington DC: US Department of Justice.

Skogan, W. G. 2006. Police and Community in Chicago: A Tale of Three Cities. New York: Oxford University Press

South African Police Service Crime Statistics 2016/2017. Available from: https://www.saps.gov.za/services/crimestats.php (Accessed 17 June 2016).

Stevens, D. J. 2002. Policing and Community Partnerships. Upper Saddle River, NJ: Prentice Hall.

Stevens, D. J. 2003. Applied Community Policing in The 21st Century. Boston: Pearson.

Thibault, E. A., Lynch, L. M. \& Mcbride, R. B. 2004. Proactive Police Management. 6th Edition. Upper Saddle River, NJ: Pearson.

Trojanowicz, R. C. \& Bucqueroux, B. 1994. Community Policing: How to Get Started. $2^{\text {nd }}$ Edition. Cincinnati: Anderson Publishers.

Van Graan, J. 2008. South African Policing in Transition: Evaluating the Impact of the Restructuring Process on the Family Violence, Child Protection and Sexual Offences Unit. PhD Thesis, University of South Africa.

Verma, A., Das, D.K. \& Abraham, M. 2013. Global Community Policing: Problems and Challenges. London: CRC Press. https://doi.org/10.1201/b12359

William, R.P. 2010. African Journal of Criminology and Justice Studies: AJCJS. Available From: http://www.faqs.org/ periodicals/201006/2080639351.html (Accessed 14 July 2016).

Wisler, G. \& Onwudiwe, F.H. 2009. Community-Oriented Policing: A Systematic Approach to Policing. Upper Saddle River, NJ: Prentice Hall.

Received on 10-12-2020

Accepted on 26-01-2021

Published on 01-02-2021

DOI: https://doi.org/10.6000/1929-4409.2021.10.27

(C) 2021 Siyanda Dlamini; Licensee Lifescience Global.

This is an open access article licensed under the terms of the Creative Commons Attribution Non-Commercial License (http://creativecommons.org/licenses/by-nc/3.0/) which permits unrestricted, non-commercial use, distribution and reproduction in any medium, provided the work is properly cited. 